\title{
Supplementation of iron alone and combined with vitamins improves haematological status, erythrocyte membrane fluidity and oxidative stress in anaemic pregnant women
}

\author{
Ai Guo Ma ${ }^{1}$, Evert G. Schouten ${ }^{2}$, Yong Ye Sun ${ }^{1}$, Fang Yang ${ }^{3}$, Xiu Xia Han ${ }^{1}$, Feng Zhi Zhang ${ }^{4}$, \\ Dian Chen Jiang 5 and Frans J. Kok ${ }^{2}$ \\ ${ }^{1}$ The Institute of Human Nutrition, Medical College of Qingdao University, Qingdao, People's Republic of China \\ ${ }^{2}$ Division of Human Nutrition, Wageningen University, Wageningen, The Netherlands \\ ${ }^{3}$ The College of Liaocheng Technology, Liaocheng, Shandong province, People's Republic of China \\ ${ }^{4}$ The People's Hospital of Liaocheng, Liaocheng, Shandong province, People's Republic of China \\ ${ }^{5}$ Service Center for Children and Women, Shen County, Shandong province, People's Republic of China \\ (Received 19 October 2009 - Revised 5 May 2010 - Accepted 1 June 2010 - First published online 9 July 2010)
}

Pregnancy is a condition exhibiting increased susceptibility to oxidative stress, and Fe plays a central role in generating harmful oxygen species. The objective of the present study is to investigate the changes in haematological status, oxidative stress and erythrocyte membrane fluidity in anaemic pregnant women after Fe supplementation with and without combined vitamins. The study was a 2 months double-blind, randomised trial. Pregnant women $(n$ 164) were allocated to four groups: group C was the placebo control group; group I was supplemented daily with $60 \mathrm{mg} \mathrm{Fe}$ (ferrous sulphate) daily; group IF was supplemented daily with Fe plus $400 \mu \mathrm{g}$ folic acid; group IM was supplemented daily with Fe plus $2 \mathrm{mg}$ retinol and $1 \mathrm{mg}$ riboflavin, respectively. After the 2-month trial, Hb significantly increased by $15.8,17.3 \mathrm{and} 21.8 \mathrm{~g} / \mathrm{l}$, and ferritin by $2.8,3.6$ and $11.0 \mu \mathrm{g} / \mathrm{l}$, in the I, IF and IM groups compared with placebo. Polarisation $(\rho)$ and microviscosity $(\eta)$ decreased significantly in other groups compared with placebo, indicating an increase in membrane fluidity. Significant decreases of $\rho$ and $\eta$ values compared with group C were 0.033 and 0.959 for group I, 0.037 and 1.074 for group IF and 0.064 and 1.865 for group IM, respectively. In addition, significant increases of glutathione peroxidase activities and decreases of malondialdehyde were shown in all treated groups, as well as increases of plasma retinol and urine riboflavin in group IM. The findings show that supplementation with Fe and particularly in combination with vitamins could improve the haematological status as well as oxidative stress and erythrocyte membrane fluidity.

Micronutrients: Anaemia: Pregnant women: Oxidative stress: Membrane fluidity

Fe is an essential trace element that is frequently deficient both in infants and in women of reproductive age from developing countries. Prevalence of anaemia is still high in rural areas in China $^{(1)}$. Fe deficiency is associated with anaemia ${ }^{(2)}$ and impairment of Fe-dependent enzymes and proteins ${ }^{(3)}$. Fe supplementation is almost universally recommended during pregnancy to correct or prevent deficiency ${ }^{(4)}$. However, the pathological accumulation of the metal within the tissues aggravates the generation of reactive oxygen species and elicits toxic effects, which are mainly related to oxidative stress $^{(5)}$. Fe plays a central role in generating harmful oxygen species. Its redox cycling promotes the Fenton reaction, producing the potent oxidant hydroxyl radical $^{(6)}$. Reactive oxygen species can alter the chemical and physical properties of cell membranes leading to a structural alteration, which could modify membrane activity and cause a reduction in membrane fluidity that can be assessed in the erythrocyte ${ }^{(7)}$. Several studies have reported that free radicals, including chemical scavengers or antioxidant molecules, superoxide dismutase (SOD) and glutathione peroxidase (GSH-Px), are relatively low in normal conditions due to active defence systems. In rats, both Fe deficiency and excess result in free radical mitochondrial damage ${ }^{(8)}$. The excessive superoxide produced by abnormal redox reactions can also cause biochemical modification in erythrocyte membrane proteins. This could result in changes in membrane structure or transmembrane transport that may exert a variety of cytotoxic effects $^{(9)}$, and affect membrane viscoelasticity.

In relation to pregnancy, there was a report that supplementation with vitamin C $(1000 \mathrm{mg} / \mathrm{d})$ and vitamin $\mathrm{E}(400 \mathrm{mg} / \mathrm{d})$ might be beneficial in pregnant women with increased risk of pre-eclampsia, a complication in which oxidation is an important feature ${ }^{(10)}$. Two large randomised trials showed, however, that supplementation with vitamins $\mathrm{C}$ and $\mathrm{E}$ during the second trimester did not reduce the pre-eclampsia ${ }^{(11,12)}$. The administration of an Fe supplement with vitamin $\mathrm{C}$ to

Abbreviations: C group, placebo control group; GSH-Px, glutathione peroxidase; I group, group supplemented daily with Fe; IF group, group supplemented daily with Fe and folic acid; IM group, group supplemented daily with Fe, folic acid, retinol and riboflavin; MDA, malondialdehyde; SOD, superoxide dismutase; $\eta$, microviscosity; $\rho$, polarisation.

* Corresponding author: Professor A. G. Ma, fax + 8653283812434 , email aiguom502@ hotmail.com 
twenty-seven women during the third trimester of pregnancy significantly increased maternal $\mathrm{Fe}$ status as well as an indicator of lipid peroxidation, compared with controls ${ }^{(13)}$. Increased oxidative stress was reported to occur in uncomplicated pregnancy and to be counteracted by a high level of plasma vitamin $\mathrm{E}^{(14)}$.

Thus, provision of a moderate dose of $\mathrm{Fe}(100 \mathrm{mg} / \mathrm{d}) \mathrm{might}$ be deleterious in certain circumstances and not in others, with respect to the possible generation of reactive oxygen species. Therefore, the purpose of the study was to investigate the effect of supplementation with Fe only and Fe combined with folic acid or with folic acid, retinol and riboflavin on haemotological status, oxidative stress parameters, such as SOD, GSH-Px and malondialdehyde (MDA) level, and erythrocyte membrane fluidity in anaemic pregnant women during the trial.

\section{Materials and methods}

\section{Participants}

The study was a 2-month intervention trial conducted on the effect of (1) Fe, (2) Fe and folic acid and (3) Fe, folic acid, retinol and riboflavin on indicators of oxidative stress, compared with placebo. Participants were recruited between March 2004 and September 2006 from the community hospitals of Shen County in the central area of China. A total of 366 pregnant women consented to participate and fulfilled the other eligibility criteria of having taken no dietary supplements during the past 2 months and having no abnormal pregnancy response. Finally, a random sample of 164 anaemic pregnant women $(80 \mathrm{~g} / \mathrm{l}<\mathrm{Hb}<110 \mathrm{~g} / \mathrm{l}), 12-24$ weeks gestation, and 20-35 years old, were randomly allocated to four groups in the order of recruitment: group C ( $n$ 41) was the placebo control group, group I ( $n$ 41) was supplemented daily with $60 \mathrm{mg} \mathrm{Fe}$ as ferrous sulphate, group IF ( $n$ 41) was supplemented daily with $60 \mathrm{mg}$ Fe and $400 \mu \mathrm{g}$ folic acid, group IM ( $n$ 41) was supplemented daily with $60 \mathrm{mg}$ $\mathrm{Fe}, 400 \mu \mathrm{g}$ folic acid, $2 \mathrm{mg}$ retinol and $1 \mathrm{mg}$ riboflavin. The sample size was calculated based on a difference in $\mathrm{Hb}$ change $(\delta)$ of $5 \mathrm{~g} / \mathrm{l}$ between the intervention and placebo groups, and a standard error of $6.67 \mathrm{~g} / \mathrm{l}$ was derived from the study reported by Suharno et al. ${ }^{(15)}$. Considering a $5 \%$ $(\alpha=0 \cdot 05)$ significance level and a power of $0.80(\beta=0 \cdot 20)$, the total number of subjects required for the study was 164 . Treatments were blindly assigned to the groups, leaving the key in a sealed envelope with an independent person in the institute. The capsules were labelled in red, yellow, green and blue colour, and manufactured by Hurun company (a Chinese food-additives company, Beijing, China). Trial participants and the research team were unaware of the treatment assignment. The trial was unblinded after analysis of the primary outcomes.

Pregnant women were enrolled after obtaining written informed consent and had a baseline interview on characteristics, such as age, gestation, and previous pregnancies. In each community, a local female community health worker called 'village nurse' was responsible for the recruitment and distribution of the supplements. After ascertainment of eligibility, consenting women were enrolled in the study, had a baseline interview and started with their allocated supplements to be taken daily for a period of 2 months. Women were home-visited once a week by the village nurse to replenish supplements and to monitor compliance by counting and recording the number of supplements that were taken. The nurse also provided counselling about the possible side effects.

The present study was conducted according to the guidelines laid down in the Declaration of Helsinki, and all the procedures involving human subjects were approved by the ethics committee of Medical College of Qingdao University (QY-ETC2002821).

\section{Sample collection and laboratory analyses}

Before and at the end of the intervention, overnight fasting $(>12 \mathrm{~h})$ blood samples were collected between 6.00 and 8.00 hours. Moreover, daily sample collection was evenly distributed over each of the four groups. The urine first passed was discarded, and the next $10 \mathrm{ml}$ was collected in dark containers, which were immediately aliquoted, for riboflavin and creatinine analysis. The samples were transported on dry-ice and stored frozen at $-80^{\circ} \mathrm{C}$ until analysis. The baseline and final samples were analysed in duplicate during the same analytic run.

Plasma retinol concentrations were measured by reversedphase HPLC (Beckman 5000 with detector of 168; Fullerton, CA, USA), and the within-assay and between assay CV were 3 and $8 \%$, respectively ${ }^{(16)}$. Folic acid in plasma was measured by the RIA method. The nutritional status of riboflavin was determined by the ratio of urine riboflavin:creatinine ${ }^{(17)}$.

$\mathrm{Hb}$ concentration was measured by the cyanomethaemoglobin method by using HemoCue for confirmation. The cutoff value of anaemia was $\mathrm{Hb}<110 \mathrm{~g} / \mathrm{l}$. Measurements of serum ferritin were performed by RIA ${ }^{(18)}$, as described by the manufacturer (The North Biological Technology Institute, Beijing, China). Plasma Fe concentrations were analysed by atomic absorption spectrometry on an Analyst 3100 Analyser (Perkin Elmer Life Sciences, Wellesley, MA, USA).

The activities of SOD and GSH-Px were determined in plasma $^{(19)}$ as U/ml and IU/ml, respectively. The MDA concentration was determined by using the thiobarbituric acid reaction, and calculated by comparing the absorbance values of the samples with those of standard MDA solutions. Results were expressed as $\mathrm{nmol} / \mathrm{ml}$ blood. Additionally, routine parameters were also studied in plasma from the subjects ${ }^{(20)}$.

The erythrocyte membrane fluidity can be measured by fluorescence polarisation $(\rho)$ and microviscosity $(\eta)$. To evaluate membrane fluidity by fluorescence spectroscopy, cell suspensions were incubated with the fluorescence probes (final concentration $\left.10^{-6} \mathrm{M}\right)$. Erythrocytes were washed with the physiological saline, and suspended in the PBS solution $(\mathrm{pH}=7.4)$ at $0.01 \mathrm{~mol} / \mathrm{l}$. To the erythrocytes suspension, 1,6-diphenyl-1,3,5-hexatriene $\left(2 \times 10^{-6} \mathrm{~mol} / \mathrm{l}\right)$ was added before being incubated in a water-bath at $25^{\circ} \mathrm{C}$ for 15 min $^{(21)}$. Samples were illuminated with the linear (vertically $-\mathrm{V}$ or horizontally $-\mathrm{H}$ ) polarised monochromatic light $\left(\lambda_{\text {ex }}\right)$, and the emitted fluorescence intensities $(I-$ in arbitrary units) parallel or perpendicular to the direction of the excitation beam were recorded. The suspension was examined by spectrofluorophotometer (Perkin Elmer fluorescence spectrometer, LS-50) with the excitation wavelength of $320 \mathrm{~nm}$ and emission wavelength of $430 \mathrm{~nm}^{(22,23)} ; \rho$ and $\eta$ of the erythrocyte membrane were calculated by the following 


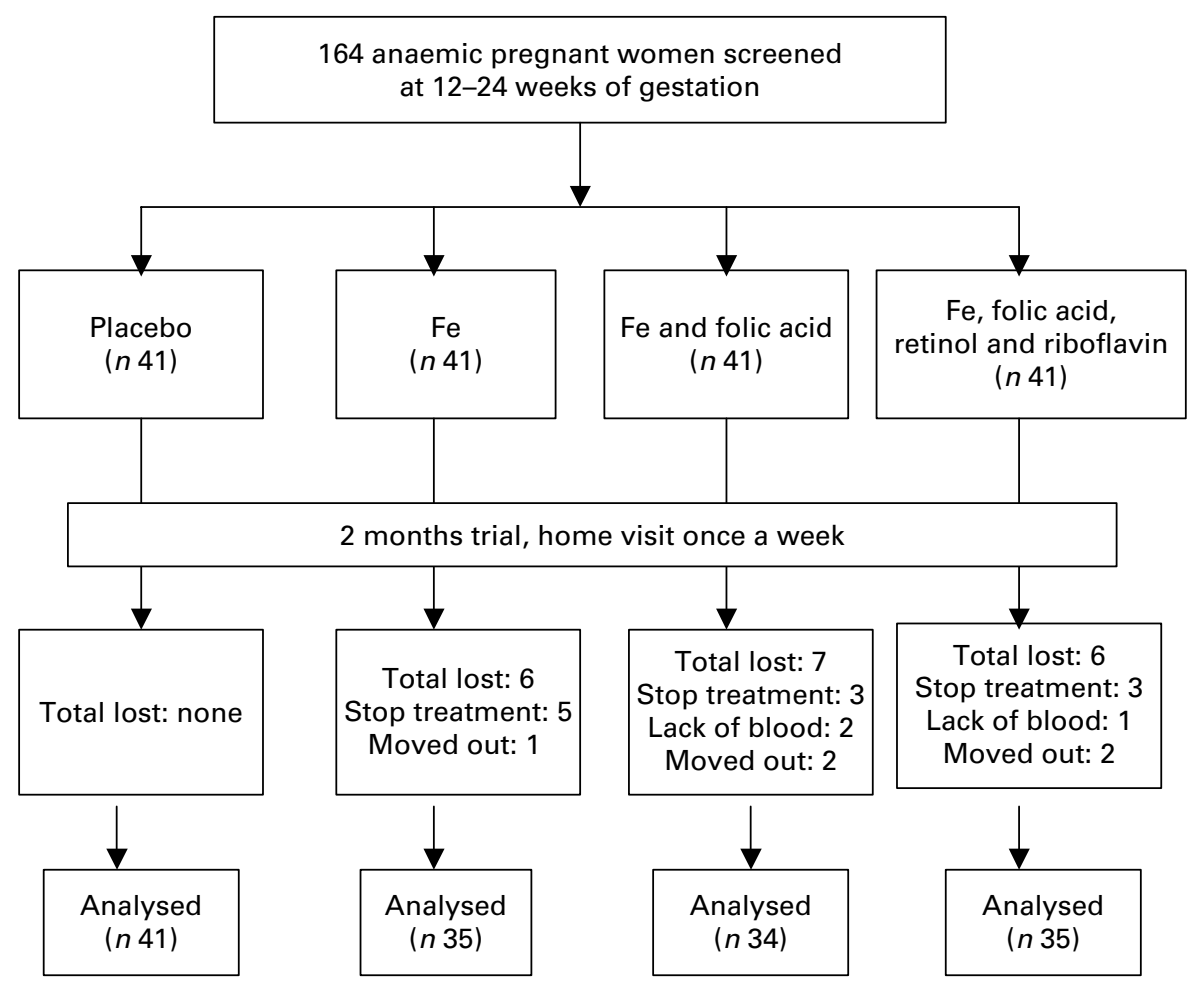

Fig. 1. The trial profile. The trial enrolment was conducted from 2004 to 2006 . A total of 366 women were eligible, from whom we took a random sample of 164 who were allocated to the intervention groups by order of randomisation. In the intervention study, complete data were available on 145 pregnant women, which is $88.4 \%$ of the original number of 164 pregnant women. Nineteen women did not complete the trial. However, there were no substantial differences between the groups in any of the baseline characteristics.

formulae:

$$
\rho=I_{\mathrm{VV}}-G I_{\mathrm{VH}} / I_{\mathrm{VV}}+G I_{\mathrm{VH}}, \eta=2 \rho / 0 \cdot 46-\rho
$$

where the indices $\mathrm{V}$ and $\mathrm{H}$ denote the vertical and horizontal position of the polariser in the excitation and the fluorescence beams, respectively. $G$ is an instrumental correction factor equal to $\left(I_{\mathrm{VV}} / I_{\mathrm{VH}}\right)$. The subscript $\mathrm{H}$ refers to the horizontally polarised excitation beam. $I_{\mathrm{VV}}$ and $I_{\mathrm{VH}}$ represent the components of the corrected polarised emission parallel and perpendicular to vertical direction, respectively ${ }^{(24,25)}$.

\section{Statistical analysis}

Categorical data are presented as frequencies, such as prevalence of anaemia. Continuous data, haematological indicators, vitamin concentrations, oxidative parameters, $\eta$ and $\rho$ values were normally distributed and presented as means and standard deviations. Baseline variables were compared across the treatment groups using a general linear model ANOVA. Mean changes over the intervention period and differences between the groups were tested with Student $t$ tests for haematological indicators, vitamin levels, oxidative indicators, $\eta$ and $\rho$ values. A two-sided $P<0.05$ was considered as the significant level for all tests.

\section{Results}

Complete data were available for 145 of the original 164 pregnant women. Nineteen women did not complete the trial for the following reasons: five women were moved to other villages, eleven women were stopped taking supplements and three women were not willing to provide a second blood sample. There were no substantial differences between the remaining groups in any of the baseline characteristics (Fig. 1 and Table 1). Compared with the means of haematological status at the start of the trial, significant decreases of $\mathrm{Hb}$, plasma $\mathrm{Fe}$ and ferritin values were found in the $\mathrm{C}$ group 2 months later, whereas the levels of haematological status were significantly increased in the I, IF and IM groups after 2 months supplementation (Fig. 2).

After the 2 months supplementation, there were considerable increases in haematological indicators in the I, IF and IM groups compared with the $\mathrm{C}$ group: $15.8,17.3$ and $21.8 \mathrm{~g} / \mathrm{l}$ for $\mathrm{Hb}$ (all $P$ values $<0.001$ ); $4.7,5.5$ and $9.7 \mu \mathrm{mol} / 1$ for plasma Fe (all $P$ values $<0.001$ ); $2.8,3.6$ and $11.0 \mu \mathrm{g} / \mathrm{l}$ for ferritin (all $P$ values $<0.001)$. The increases of plasma retinol and urine riboflavin in the IM group were $267.4 \mu \mathrm{g} / \mathrm{l}(P<0.001))$ and $61.59 \mathrm{mg} / \mathrm{g}$ creatinine $(P<0.001)$, respectively. For plasma folic acid, the increase was $4.06 \mu \mathrm{g} / \mathrm{l}$ in the IF group $(P<0.001)$ and $4.65 \mu \mathrm{g} / \mathrm{l}$ in the IM group $(P<0.001)$, all compared with the $\mathrm{C}$ group (Table 2). The increases in all haematological and vitamin indicators in the IM group were significantly greater than in the I group (all $P$ values $<0.001$ ).

Erythrocyte membrane fluidity was evaluated using fluorescence $\rho$ and $\eta$; lower values indicate better membrane fluidity. After the trial, the $\rho$ and $\eta$ values, compared with the $\mathrm{C}$ group, decreased by 0.033 and 0.959 for the I group, 0.037 and 1.074 for the IF group, and 0.064 and 1.865 for the IM group, respectively. The $\rho$ and $\eta$ values in the IM compared with those in the I group decreased by $0 \cdot 031$ and $0 \cdot 906$ (all $P$ values $<0.05$ ) (Table 3 ). 
Table 1. Baseline characteristics of Chinese anaemic pregnant women in four groups* (Mean values and standard deviations)

\begin{tabular}{|c|c|c|c|c|c|c|c|c|c|c|c|c|}
\hline \multirow[b]{2}{*}{ Characteristics } & \multicolumn{2}{|c|}{ All baseline } & \multicolumn{2}{|c|}{ C } & \multicolumn{2}{|c|}{1} & \multicolumn{2}{|c|}{ IF } & \multicolumn{2}{|c|}{$\mathrm{IM}$} & \multirow[b]{2}{*}{$F$} & \multirow[b]{2}{*}{$P \dagger$} \\
\hline & Mean & SD & Mean & SD & Mean & SD & Mean & SD & Mean & SD & & \\
\hline Subjects $(n)$ & \multicolumn{2}{|c|}{145} & \multicolumn{2}{|c|}{41} & \multicolumn{2}{|c|}{35} & \multicolumn{2}{|c|}{34} & \multicolumn{2}{|c|}{35} & & \\
\hline Age (years) & $27 \cdot 4$ & $3 \cdot 4$ & $27 \cdot 3$ & 3.4 & $27 \cdot 8$ & 3.5 & $27 \cdot 4$ & $3 \cdot 1$ & $27 \cdot 0$ & 3.7 & 0.62 & 0.601 \\
\hline Gravidity $(n)$ & 1.3 & 0.4 & 1.3 & 0.5 & 1.3 & 0.5 & 1.3 & 0.4 & 1.2 & 0.4 & 0.86 & 0.464 \\
\hline Gestational stage (week) & $20 \cdot 9$ & 4.7 & $21 \cdot 1$ & 4.8 & $21 \cdot 9$ & 4.4 & $20 \cdot 0$ & 4.8 & $20 \cdot 3$ & 4.5 & 1.28 & 0.285 \\
\hline $\mathrm{Hb}(\mathrm{g} / \mathrm{l})$ & $99 \cdot 8$ & 6.5 & $101 \cdot 7$ & $8 \cdot 7$ & 99.5 & $5 \cdot 6$ & $99 \cdot 0$ & 4.8 & $98 \cdot 8$ & $5 \cdot 7$ & 0.76 & 0.519 \\
\hline Plasma Fe $(\mu \mathrm{mol} / \mathrm{l})$ & $12 \cdot 2$ & $2 \cdot 1$ & $12 \cdot 8$ & $2 \cdot 8$ & $11 \cdot 6$ & $2 \cdot 3$ & $11 \cdot 7$ & 1.5 & $12 \cdot 3$ & $1 \cdot 2$ & 1.88 & 0.136 \\
\hline Ferritin $(\mu \mathrm{g} / \mathrm{l})$ & $12 \cdot 1$ & $3 \cdot 8$ & $12 \cdot 6$ & $5 \cdot 1$ & $12 \cdot 8$ & $2 \cdot 6$ & 11.9 & $3 \cdot 3$ & $10 \cdot 9$ & $3 \cdot 6$ & $0 \cdot 76$ & 0.521 \\
\hline Folate $(\mu \mathrm{g} / \mathrm{l})$ & 3.90 & 1.84 & $4 \cdot 10$ & 1.86 & 3.68 & 1.65 & $4 \cdot 13$ & 1.95 & 3.66 & 1.92 & 0.21 & 0.891 \\
\hline Retinol $(\mu \mathrm{g} / \mathrm{l}))$ & $296 \cdot 8$ & 67.5 & $306 \cdot 9$ & 79.5 & $301 \cdot 3$ & $62 \cdot 2$ & $297 \cdot 8$ & $61 \cdot 3$ & $279 \cdot 3$ & $62 \cdot 0$ & $2 \cdot 8$ & 8.42 \\
\hline Riboflavin (mg/g creatinine ratio) & 41.95 & $15 \cdot 39$ & $42 \cdot 29$ & $17 \cdot 64$ & 42.98 & $14 \cdot 10$ & $42 \cdot 52$ & 14.75 & 39.96 & 14.90 & 0.08 & 0.969 \\
\hline Malondialdehyde $(\mu \mathrm{mol} / \mathrm{l})$ & 4.97 & 1.34 & 4.95 & $1 \cdot 10$ & $5 \cdot 38$ & 1.77 & 4.68 & $1 \cdot 11$ & 4.88 & $1 \cdot 28$ & 1.57 & 0.200 \\
\hline Superoxide dismutase $(\mathrm{U} / \mathrm{ml})$ & $73 \cdot 3$ & $26 \cdot 2$ & $73 \cdot 3$ & $35 \cdot 1$ & $72 \cdot 3$ & $22 \cdot 4$ & $73 \cdot 8$ & $23 \cdot 3$ & 73.7 & $20 \cdot 7$ & 0.02 & 0.995 \\
\hline Glutathione peroxidase (IU/ml) & $116 \cdot 6$ & $29 \cdot 0$ & $108 \cdot 3$ & $26 \cdot 7$ & $116 \cdot 3$ & $27 \cdot 1$ & $124 \cdot 2$ & 30.7 & $119 \cdot 4$ & $30 \cdot 2$ & 2.06 & 0.108 \\
\hline
\end{tabular}

* Group C, placebo; group I, $60 \mathrm{mg}$ ferrous sulphate; group IF, in addition $400 \mu \mathrm{g}$ folic acid; group IM, in addition $2 \mathrm{mg}$ retinol and $1 \mathrm{mg}$ riboflavin †One-way ANOVA.

The changes in oxidative stress parameters are presented in Table 3. Compared with the $\mathrm{C}$ group, increases of GSH-Px activities were $37.7,43.4$ and $87.9 \mathrm{IU} / \mathrm{ml}$ in the I, IF and IM groups, respectively; the levels of MDA decreased by 0.55 , 1.06 and $2.56 \mu \mathrm{mol} / \mathrm{l}$. Moreover, the increase of GSH-Px activity and decrease of MDA level were $50 \cdot 2 \mathrm{IU} / \mathrm{ml}$ and $2.01 \mu \mathrm{mol} / 1$ greater in the IM group compared with the I group (all $P$ values $<0.01$ ); however, there were no important changes in SOD activities during the trial.

\section{Discussion}

After 2 months of supplementation with $\mathrm{Fe}$ and/or vitamins, anaemic pregnant women significantly improved in erythrocyte membrane fluidity and antioxidative markers, in addition to increases of $\mathrm{Hb}$ concentration, plasma $\mathrm{Fe}$, ferritin, retinol and urine riboflavin concentrations. Most of the effects were greatest in the Fe combined with multivitamin (IM) group.

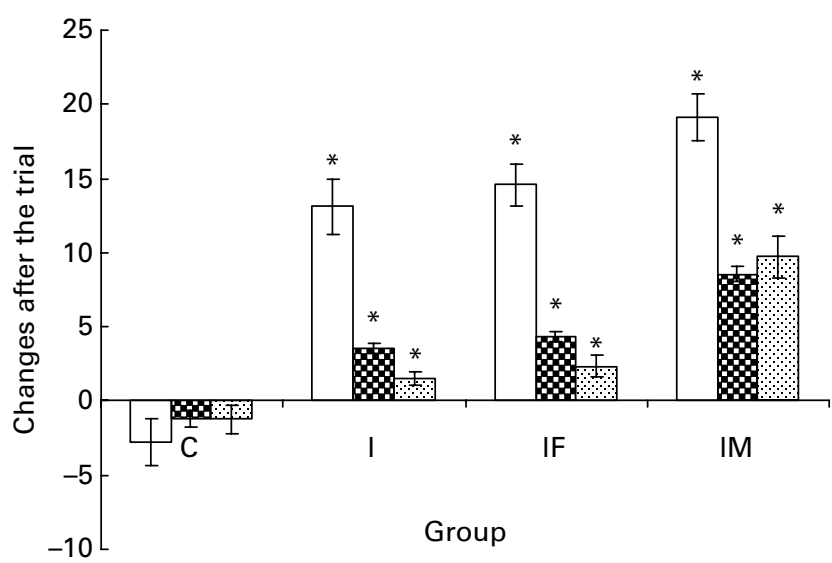

Fig. 2. A comparison of haematological status between before and after the trial. $\square$ represent the mean and standard deviation of $\mathrm{Hb}$ concentration, for plasma iron concentration and for ferritin with significant changes between groups; group $\mathrm{C}$ as placebo, group I supplemented daily with $60 \mathrm{mg}$ iron, IF with $60 \mathrm{mg}$ iron and $400 \mu \mathrm{g}$ folic acid and IM with $60 \mathrm{mg}$ iron, $400 \mu \mathrm{g}$ folic acid, $2 \mathrm{mg}$ retinol and $1 \mathrm{mg}$ riboflavin, respectively. ${ }^{*}$ Mean values were significantly different from that of the control group $(P<0.05)$.
Up to now, only few studies have evaluated the changes in both haematological status and erythrocyte membrane fluidity after Fe supplementation in anaemic pregnant women, possibly because erythrocyte membrane preparation is quite laborious. The present study had a relatively large study population and it was carried out under difficult circumstances in a poor rural part of China. Unfortunately, there was a small proportion of women who dropped out after treatment allocation, only in the supplement groups. Some subjects stopped treatment because of possible side effects, including nausea, abdominal discomfort and vomiting ${ }^{(26)}$. For other subjects, data were not complete because of an insufficient amount of plasma, subjects refusing to give a second blood sample or they were moving out of the area. This did not result in imbalances with respect to important baseline characteristics. Compliance of the remaining participants was almost complete, probably because the study subjects were motivated by the offer of free of charge medical care, and bi-weekly visits by village nurses.

In fact, retinol and riboflavin deficiencies tend to coexist in anaemic pregnant women in developing countries or in impoverished settings ${ }^{(27)}$. In a previous study ${ }^{(1)}$, high percentages of subnormal vitamin A and subnormal riboflavin were 23 and $38 \%$ in anaemic pregnant women. Vitamin A deficiency may also result in anaemia in human subjects and animals that can be reversed only by vitamin A supplementation ${ }^{(28)}$. Biochemical evidence of riboflavin deficiency was documented during the third trimester of pregnancy ${ }^{(29)}$. Retinol or riboflavin plus Fe supplementation could improve haematological status better than $\mathrm{Fe}$ alone ${ }^{(30)}$. The reduced prevalence of anaemia $(\mathrm{Hb}<110 \mathrm{~g} / \mathrm{l})$ and Fe-deficiency anaemia was significantly greater in the groups supplemented with retinol and/or riboflavin than in the groups supplemented with Fe. Retinol status is a putative factor for improved $\mathrm{Fe}$ status or Fe absorption. Vitamin A and $\beta$-carotene may form a complex with Fe, keeping it soluble in the intestinal lumen as well as preventing the inhibitory factors on $\mathrm{Fe}$ absorption ${ }^{(31)}$. Moreover, gastrointestinal symptoms were less prevalent in the group supplemented with $\mathrm{Fe}$, folic acid and retinol than in the group supplemented with $\mathrm{Fe}$ only, and improved well-being was more prevalent in the groups that received additional retinol and/or riboflavin than in the group that received $\mathrm{Fe}$ only. 
Table 2. Comparison of haematological and vitamin status between control and supplemented groups ${ }^{\star}$ after the trial (Mean values and standard deviations)

\begin{tabular}{|c|c|c|c|c|c|c|c|c|c|c|}
\hline \multirow[b]{2}{*}{ Indicators } & \multicolumn{2}{|c|}{ C } & \multicolumn{2}{|c|}{1} & \multicolumn{2}{|c|}{ IF } & \multicolumn{2}{|c|}{ IM } & \multirow[b]{2}{*}{$F$} & \multirow[b]{2}{*}{$P \dagger$} \\
\hline & Mean & SD & Mean & SD & Mean & SD & Mean & SD & & \\
\hline Subjects $(n)$ & \multicolumn{2}{|c|}{41} & \multicolumn{2}{|c|}{35} & \multicolumn{2}{|c|}{34} & \multicolumn{2}{|c|}{35} & & \\
\hline $\mathrm{Hb}(\mathrm{g} / \mathrm{l})$ & $99 \cdot 0^{\mathrm{a}}$ & 5.5 & $114 \cdot 8^{b}$ & $8 \cdot 6$ & $116 \cdot 3^{\mathrm{C}}$ & $6 \cdot 0$ & $120 \cdot 8^{d}$ & $6 \cdot 1$ & $80 \cdot 38$ & 0.000 \\
\hline Plasma Fe $(\mu \mathrm{mol} / \mathrm{l})$ & $11.6^{\mathrm{a}}$ & 1.9 & $16 \cdot 3^{b}$ & 0.5 & $17 \cdot 1^{\mathrm{c}}$ & 0.8 & $21 \cdot 3^{\mathrm{d}}$ & 1.5 & 344.95 & 0.000 \\
\hline Ferritin $(\mu \mathrm{g} / \mathrm{l})$ & $11.4^{\mathrm{a}}$ & 3.4 & $14 \cdot 2^{\mathrm{b}}$ & 1.2 & $15 \cdot 0^{\mathrm{c}}$ & $2 \cdot 2$ & $22 \cdot 4^{\mathrm{d}}$ & $6 \cdot 4$ & $55 \cdot 14$ & 0.000 \\
\hline Folic acid $(\mu \mathrm{g} / \mathrm{l})$ & $3.52^{\mathrm{a}}$ & 1.50 & $4 \cdot 12$ & $1 \cdot 29$ & $7 \cdot 58^{c}$ & 1.67 & $8 \cdot 17^{d}$ & 1.74 & 83.44 & 0.000 \\
\hline Retinol $(\mu \mathrm{g} / \mathrm{l})$ & $290 \cdot 5^{\mathrm{a}}$ & 63.4 & $313 \cdot 1$ & $55 \cdot 8$ & 314.8 & $49 \cdot 3$ & $557 \cdot 9^{d}$ & $90 \cdot 0$ & $1296 \cdot 8$ & 0.000 \\
\hline Riboflavin (mg/g creatinine ratio) & $39.79^{\mathrm{a}}$ & $15 \cdot 56$ & $47 \cdot 17$ & $20 \cdot 03$ & 47.05 & $19 \cdot 16$ & $101 \cdot 38^{d}$ & $46 \cdot 40$ & 37.91 & 0.000 \\
\hline
\end{tabular}

a,b,c,d Mean values within a row with unlike superscript letters were significantly different $(P<0.05$, independent $t$ test).

* Group C, placebo; group I, $60 \mathrm{mg}$ ferrous sulphate; group IF, in addition $400 \mu \mathrm{g}$ folic acid; group IM, in addition $2 \mathrm{mg}$ retinol and $1 \mathrm{mg}$ riboflavin.

†One-way ANOVA.

Although fluorescence $\rho$ was used to assess membrane fluidity in the past decades, presently, it is frequently applied in estimating oxidative stress ${ }^{(32)}$, erythrocyte aggregation ${ }^{(33)}$, understanding of membrane protein function ${ }^{(34)}$, etc. The noninvasiveness of the method makes it especially suitable for clinical applications ${ }^{(35)}$. Pregnancy is a condition exhibiting increased susceptibility to oxidative stress. In normal pregnancy, the implantation process, proliferation, differentiation and trophoblast invasion produce reactive oxygen species $^{(36,37)}$. Transitional metals, especially $\mathrm{Fe}$, which are particularly abundant in the placenta, are important in the production of these free radicals ${ }^{(38)}$. Increased $\mathrm{Fe}$ levels may be responsible for placental oxidative stress and abnormalities in antioxidants ${ }^{(39)}$. Fe overload could promote the generation of free radicals and result in cellular damage ${ }^{(12)}$, and Fe supplementation with $100 \mathrm{mg} / \mathrm{d}$ or overload might risk increased MDA levels or oxidative stress in the maternal plasma and the placenta during pregnancy ${ }^{(40)}$, but in a previous study, low doses of oral ferrous $\mathrm{Fe}(36 \mathrm{mg} / \mathrm{d})$ did not unfavourably change the physiological pattern of parameters of oxidation $^{(41)}$. However, in the present study, haemotological status was improved and MDA levels decreased in anaemic pregnant women after a daily supplementation of $60 \mathrm{mg} \mathrm{Fe}$, which might be attributed to the supplementation with a low dose of Fe and a combination of three vitamins. Erythrocyte membrane fluidity also improved, which indicates that the
$\mathrm{Fe}$ supplementation did not reduce, but possibly even improved, the antioxidant capacity. There are no documented side effects of Fe supplements below $100 \mathrm{mg} / \mathrm{d}^{(42)}$. In the present study, Fe combined with multivitamin supplementation showed a more favourable effect than $\mathrm{Fe}$ alone, and this dose of $\mathrm{Fe}$ supplementation did not increase $\mathrm{Hb}$ levels higher than the optimal concentration needed for $\mathrm{O}_{2}$ delivery ${ }^{(43)}$. A daily supplementation of $100 \mathrm{mg} \mathrm{Fe}$ as ferrous sulphate was recommended during the second half of pregnancy to address the corresponding $\mathrm{Fe}$ requirements ${ }^{(2)}$, and the risks associated with oxidative stress were not observed in women supplemented with $120 \mathrm{mg} \mathrm{Fe}$ once or twice per week ${ }^{(38)}$. Suggested guidelines are ferritin $<30 \mu \mathrm{g} / \mathrm{l}: 80-100 \mathrm{mg}$ ferrous Fe daily, for which there are no documented side effects ${ }^{(42)}$.

Several studies have shown that micronutrient supplementation improves the GSH-Px activities and decreases the levels of $\mathrm{MDA}^{(20,44)}$, and antioxidant supplementation was associated with better maternal and perinatal outcome in pregnant women with low antioxidant status than supplementation with $\mathrm{Fe}$ and folate alone ${ }^{(45)}$. However, we did not find any change of SOD activity during the trial. Some studies showed similar results ${ }^{(46)}$ and even a decrease of SOD activity after antioxidant supplementation ${ }^{(47)}$. This aspect deserves further study. In the present study, antioxidant defences and oxidative stress appear to be favourably modulated by

Table 3. Comparison of membrane fluidity and oxidative stress status between control and supplemented groups ${ }^{*}$ after the trial (Mean values and standard deviations)

\begin{tabular}{|c|c|c|c|c|c|c|c|c|c|c|}
\hline \multirow[b]{2}{*}{ Indicators } & \multicolumn{2}{|c|}{ C } & \multicolumn{2}{|c|}{1} & \multicolumn{2}{|c|}{ IF } & \multicolumn{2}{|c|}{ IM } & \multirow[b]{2}{*}{$F$} & \multirow[b]{2}{*}{$P \dagger$} \\
\hline & Mean & SD & Mean & SD & Mean & SD & Mean & SD & & \\
\hline Subjects $(n)$ & \multicolumn{2}{|c|}{41} & \multicolumn{2}{|c|}{35} & \multicolumn{2}{|c|}{34} & \multicolumn{2}{|c|}{35} & & \\
\hline Membrane fluidity & & & & & & & & & & \\
\hline$\rho$ & $0.330^{\mathrm{a}}$ & 0.052 & $0.297^{b}$ & 0.012 & $0.293^{C}$ & 0.008 & $0.266^{d}$ & 0.009 & $30 \cdot 81$ & 0.000 \\
\hline$\eta$ & $4.593^{a}$ & 2.088 & $3.634^{\mathrm{b}}$ & 0.419 & $3.519^{C}$ & 0.243 & $2 \cdot 728^{d}$ & 0.178 & $17 \cdot 12$ & 0.000 \\
\hline \multicolumn{11}{|l|}{ Oxidative stress } \\
\hline GSH-Px (IU/ml) & $115 \cdot 1^{\mathrm{a}}$ & 23.5 & $152 \cdot 8^{\mathrm{b}}$ & $60 \cdot 0$ & $158 \cdot 5^{\mathrm{c}}$ & 63.8 & $203.0^{\mathrm{d}}$ & 88.5 & $12 \cdot 62$ & 0.000 \\
\hline $\mathrm{SOD}(\mathrm{U} / \mathrm{ml})$ & 72.5 & 35.9 & $76 \cdot 0$ & $19 \cdot 6$ & $75 \cdot 1$ & $17 \cdot 7$ & 72.9 & $18 \cdot 3$ & 0.17 & 0.915 \\
\hline $\mathrm{MDA}(\mu \mathrm{mol} / \mathrm{l})$ & $5 \cdot 04^{\mathrm{a}}$ & $1 \cdot 12$ & $4.49^{b}$ & 0.57 & $3.98^{\mathrm{c}}$ & 0.60 & $2 \cdot 48^{d}$ & 0.46 & 78.34 & 0.000 \\
\hline
\end{tabular}

$\rho$, Polarisation; $\eta$, microviscosity; GSH-Px, glutathione peroxidase; SOD, superoxide dismutase; MDA, malondialdehyde.

a,b,c,d Mean values within a row with unlike superscript letters were significantly different $(P<0.05$; independent $t$ test).

* Group C, placebo; group I, $60 \mathrm{mg}$ ferrous sulphate; group IF, in addition $400 \mu \mathrm{g}$ folic acid; group IM, in addition $2 \mathrm{mg}$ retinol and $1 \mathrm{mg}$ riboflavin

†One-way ANOVA. 
Fe supplementation alone. Such findings have not been reported in anaemic pregnant women before, and further mechanistic studies are to be expected.

Taken together, subjects had more antioxidative capacity, i.e. lower levels of circulating lipid peroxidation products (MDA), and higher GSH-Px activity and higher vitamin concentrations after 2 months of supplementation. The improvement of erythrocyte membrane fluidity, as apparent in decreases of $\rho$ and $\eta$, indicates that the erythrocytes accumulate fewer oxidative lesions. Moreover, the increase in the plasma antioxidant status could contribute to the prevention of PUFA peroxidation of erythrocytes. This evidence could also explain the lower peroxidation found in subjects supplemented with Fe and vitamins in comparison with the control. Fe combined with multivitamin supplementation showed a more favourable effect than $\mathrm{Fe}$ only. We could not find any indication of an increase of oxidative stress after Fe supplementation. On the contrary, a moderate dose of Fe, preferably combined with multivitamin supplementation, may be beneficial both by improving anaemia and by decreasing the status of oxidative stress during pregnancy.

\section{Acknowledgements}

We thank the Nestlé Foundation and the Danone Nutrition Institute, China, for financial support. A. G. M. and E. G. S. designed the intervention study. Y. Y. S., F. Y., F. Z. Z. and D. C. J. conducted investigation in field sites, data collection, analyses and interpretation and laboratory analyses. X. X. H. analysed the data. A. G. M., E. G. S. and F. J. K. wrote the paper. There are no conflicts of interest.

\section{References}

1. Ma AG, Schouten EG, Wang Y, et al. (2009) Anemia prevalence among pregnant women and birth weight in five areas in China. Med Princ Pract 18, 368-372.

2. Schümann K, Ettle T, Szegner B, et al. (2007) On risks and benefits of iron supplementation recommendations for iron intake revisited. J Trace Elem Med Biol 21, 147-168.

3. Beard JL \& Dawson HD (1997) Iron. In Handbook of Nutritionally Essential Elements [BL O'Dell and RA Sunde, editors]. New York: Marcel Dekker Inc.

4. Stoltzfus RJ \& Dreyfuss ML (1998) Guidelines for the Use of Iron Supplements to Prevent and Treat Iron Deficiency Anemia. Washington, DC: International Nutritional Anemia Consultative Group, International Life Sciences Institute.

5. Galaris D \& Pantopoulos K (2008) Oxidative stress and iron homeostasis: mechanistic and health aspects. Crit Rev Clin Lab Sci 45, 1-23.

6. Halliwell B \& Gutteridge JC (1985) Oxygen toxicity, oxygen radicals, transition metals and disease. Biochem $J$ 219, 1-14.

7. Lutz HU (1990) Erythrocyte clearance. In Blood Cell Biochemistry, vol. 1, pp. 81-90. New York: Plenum.

8. Srigiridhar K, Nair KM, Subramanian R, et al. (2001) Oral repletion of iron induces free radical mediated alterations in the gastrointestinal tract of rat. Mol Cell Biochem 219, 91-98.

9. Uyesaka N, Hasegawa S \& Schechter AN (1992) Effects of superoxide anions on red cell deformability and membrane proteins (Abstract). Biorheology 29, 217-229.

10. Chappell LC, Seed PT, Briley AL, et al. (1999) Effect of antioxidants on the occurrence of pre-eclampsia in women at increased risk: a randomised trial. Lancet 354, 810-816.
11. Poston L, Briley AL, Seed PT, et al. (2006) Vitamin C and vitamin E in pregnant women at risk for pre-eclampsia (VIP trial): randomised placebo controlled trial. Lancet 367, 1145-1154.

12. Rumbold AR, Crowther CA, Haslam RR, et al. (2006) Vitamins $\mathrm{C}$ and $\mathrm{E}$ and the risks of preeclampsia and perinatal complications. N Engl J Med 354, 1796-1806.

13. Lachili B, Hininger I, Faure H, et al. (2001) Increased lipid peroxidation in pregnant women after iron and vitamin $\mathrm{C}$ supplementation. Biol Trace Elem Res 83, 103-110.

14. Cargnoni AA, Gregorini G, Ceconi C, et al. (1994) Lipid peroxidation in normal pregnancy and preeclampsia. Adv Exp Med Biol 366, 420-423.

15. Suharno D, West CE, Karyadi MD, et al. (1993) Supplementation with vitamin A and iron for nutritional anemia in pregnant women in west Java Indonesia. Lancet 342, 1325-1328.

16. Handelman GJ, Shen B \& Krinsky NI (1992) High resolution analysis of carotenoids in human plasma by high-performance liquid chromatography. Methods Enzymol 213, 336-346.

17. Sauberlich HE, Judd JH Jr, Nichoalds GE, et al. (1972) Application of the erythrocyte glutathione reductase assay in evaluating riboflavin nutritional status in a high school student population. Am J Clin Nutr 25, 756-762.

18. Liu ZW, Han QY, Zhang N, et al. (2004) Sequential changes of serum ferritin levels and their clinical significance in lamivudine-treated patients with chronic viral hepatitis B. World $J$ Gastroenterol 10, 972-976.

19. Durak I, Canbolat O, Kavutcu M, et al. (1996) Activities of total, cytoplasmic and mitochondrial superoxide dismutase enzymes in sera and pleural fluids from patients with lung cancer. J Clin Lab Anal 10, 17-20.

20. Avci A, Atli T, Ergüder IB, et al. (2008) Effects of garlic consumption on plasma and erythrocyte antioxidant parameters in elderly subjects. Gerontology 54, 173-176.

21. Xue ML, Hou JM, Zhang XZ, et al. (2006) Effect of Kiwifruit extracts on plasma lipids and erythrocyte membrane fluidity in hyperlipidemic rats. Acta Nutrimenta Sinica 28, 350-351.

22. Sun YY, Ma AG \& Zhang XZ (2005) Effects of vitamin C on the antioxidant ability and erythrocyte membrane fluidity in guinea pig. Wei Sheng Yan Jiu 34, 329-330.

23. Ortiz GG, Pacheco-Moisés F, El Hafidi M, et al. (2008) Detection of membrane fluidity in submitochondrial particles of platelets and erythrocyte membranes from Mexican patients with Alzheimer disease by intramolecular excimer formation of 1,3 dipyrenylpropane. Dis Markers 24, 151-156.

24. Tang X, Xia Z \& Yu J (2007) An experimental study of hemolysis induced by onion (Allium cepa) poisoning in dogs. $J$ Vet Pharmacol Therap 31, 143-149.

25. Marczak A (2009) Fluorescence anisotropy of membrane fluidity probes in human erythrocytes incubated with anthracyclines and glutaraldehyde. Bioelectrochemistry 74, 236-239.

26. Ma AG, Schouten EG, Zhang FZ, et al. (2008) Retinol and riboflavin supplementation decreases the prevalence of anemia in Chinese pregnant women taking iron and folic acid supplements. J Nutr 138, 1946-1950.

27. Bates CJ, Prentice AM \& Paul AA (1994) Seasonal variations in vitamin A, C, riboflavin and folate intakes and status of pregnant and lactating women in a rural Gambian community: some possible implications. Eur J Clin Nutr 48, 660-668.

28. Bloem MW, Wedel M, Egger R, et al. (1989) Iron metabolism and vitamin A deficiency in children in the Northwest Thailand. Am J Clin Nutr 50, 332-338.

29. Pongpaew P, Saowakontha S, Schelp FP, et al. (1995) Vitamin $B_{1}$, $\mathrm{B}_{2}$ and $\mathrm{B}_{6}$ during the course of pregnancy of rural and urban women in northeast Thailand. Int J Vitam Nutr Res 65, 111-116.

30. Suprapto B, Widardo \& Suhanantyo (2002) Effect of lowdosage vitamin A and riboflavin on iron-folate supplementation in anaemic pregnant women. Asia Pac J Clin Nutr 11, 263-267. 
31. Semba RD \& Bloem MW (2002) The anemia of vitamin A deficiency: epidemiology and pathogenesis. Eur J Clin Nutr 56, 271-281.

32. Soto-Arriaza MA, Sotomayor CP \& Lissi EA (2008) Relationship between lipid peroxidation and rigidity in 1-alpha-phosphatidylcholine-DPPC vesicles. $J$ Colloid Interface Sci $\mathbf{3 2 3}$, $70-74$.

33. Spengler MI, Bertoluzzo SM, Catalani G, et al. (2008) Study on membrane fluidity and erythrocyte aggregation in equine, bovine and human species. Clin Hemorheol Microcirc 38, 171-176.

34. Periasamy N, Teichert H, Weise K, et al. (2009) Effects of temperature and pressure on the lateral organization of model membranes with functionally reconstituted multidrug transporter LmrA. Biochim Biophys Acta 1788, 390-401.

35. Kaneko T, Matsui H, Shimokawa O, et al. (2007) Cellular membrane fluidity measurement by fluorescence polarization in indomethacin-induced gastric cellular injury in vitro. $J$ Gastroenterol 42, 939-946.

36. Gitto E, Pellegrino S, Gitto P, et al. (2009) Oxidative stress of the newborn in the pre- and postnatal period and the clinical utility of melatonin. J Pineal Res 46, 128-139.

37. Dennery PA (2007) Effects of oxidative stress on embryonic development. Birth Defects Res C Embryo Today 81, 155-162.

38. Casanueva E \& Viteri EF (2003) Iron and oxidative stress in pregnancy. J Nutr 133, 1700S-1708S.

39. Vaughan JE \& Walsh SW (2002) Oxidative stress reproduces placental abnormalities of preeclampsia. Hypertens Pregnancy 21, 205-223.
40. Devrim E, Tarhan I, Ergüder IB, et al. (2006) Oxidant/antioxidant status of placenta, blood, and cord blood samples from pregnant women supplemented with iron. J Soc Gynecol Investig 13, 502-505.

41. Rehema A, Zilmer K, Klaar U, et al. (2004) Ferrous iron administration during pregnancy and adaptational oxidative stress (Pilot study). Medicina (Kaunas) 40, 547-552.

42. Milman N (2006) Iron prophylaxis in pregnancy - general or individual and in which dose? Ann Hematol 85, 821-828.

43. Yip R (2000) Significance of an abnormally low or high hemoglobin concentration during pregnancy: special consideration of iron nutrition. Am J Clin Nutr 72, 272S-279S.

44. Zhang M, Ma AG, Zhang XZ, et al. (2005) Effect of multiple micronutrients supplementation on anti-oxidative activity and oxidized DNA damage of lymphocytes in children. Zhonghua Liu Xing Bing Xue Za Zhi 26, 268-272.

45. Rumiris D, Purwosunu Y, Wibowo N, et al. (2006) Lower rate of preeclampsia after antioxidant supplementation in pregnant women with low antioxidant status. Hypertens Pregnancy 25, 241-253.

46. Oh HY, Lim S, Lee JM, et al. (2007) A combination of soy isoflavone supplementation and exercise improves lipid profiles and protects antioxidant defense-systems against exerciseinduced oxidative stress in ovariectomized rats. Biofactors 29, $175-185$.

47. Ahmed RS, Suke SG, Seth V, et al. (2006) Impact of oral vitamin E supplementation on oxidative stress \& lipid peroxidation in patients with polymorphous light eruption. Indian J Med Res 123, 781-787. 